\title{
REFLEXÕES SOBRE A PROPOSTA DE FORMAÇÃO DE PROFESSORES DO PNAIC PARA A EDUCAÇÃO INFANTIL
}

Cármen Maria França da Silva ${ }^{(*)}$ Débora Ortiz Leão $o^{(* *)}$

O presente texto surge a partir das reflexões acerca da orientação do Ministério da Educação em agregar no Programa Pacto Nacional pela Alfabetização na Idade Certa os professores que atuam na Educação Infantil no final do ano de 2017 e início de 2018, onde os estados e municípios realizaram a adesão a proposta, sem a necessária clareza quanto ao seu funcionamento e a compreensão dos objetivos propostos, conduzindo-nos a reflexão acerca das temáticas políticas curriculares e a formação de professores para essa etapa, tendo o Programa como eixo central dessa discussão. O objetivo é, portanto, é discutir a implementação do Programa na Educação Infantil.

Diante disso, inicialmente, realizaremos um resgate histórico sobre o PNAIC - o qual está em sintonia com a meta cinco do Plano Nacional de Educação - PNE, que trata da alfabetização das crianças até os oito anos de idade e com a Política Nacional de Formação de Profissionais do Magistério da Educação Básica, Decreto 6.755, de 29 de janeiro de 2009.

Em seguida, apresentaremos a concepção de criança e infância, tendo em vista os conceitos que se constituíram ao longo da história no Brasil e as especificidades que constituem essa etapa da Educação Básica.

Logo após, analisaremos os marcos legais e regulatórios que sustentam a ação pedagógica na Educação Infantil e as políticas de avaliação da Educação Básica que refletem nas práticas pedagógicas, no intuito de compreender os caminhos percorridos até a inclusão dessa etapa no contexto do Programa. Por fim, realizaremos uma breve análise da proposta construída pelo PNAIC para a Educação Infantil, na tentativa de elucidar a sua repercussão nas práticas educativas.

\footnotetext{
${ }^{(*)}$ Mestranda do Programa de Pós-graduação em Políticas Públicas e Gestão Educacional na Universidade Federal de Santa Maria (UFSM). Especialista em Psicopedagogia/Centro Universitário Franciscano (UNIFRA). Pedagoga. Chefe Pedagógica da $8^{a}$ Coordenadoria Regional de Educação/SM. Tutora Curso de Pedagogia a Distância/ Universidade Federal de Santa Maria. Orcid: <https://orcid.org/0000-0001-8700-2014. http://lattes.cnpq.br/0254779922402603>. Email: carmenfranca@gmail.com

${ }^{(* *)}$ Doutora em Educação pela Pontifícia Universidade Católica do RS. Mestre em Educação pela Universidade Federal de Santa Maria (UFSM). Especialista em Psicopedagogia Institucional pela Universidade da Região da Campanha. Graduada em Pedagogia pela Faculdade de Filosofia Ciências e Letras Imaculada Conceição. Professora Associada na UFSM, onde desempenha atividades profissionais vinculadas ao Departamento de Administração Escolar, do Centro de Educação. Ordic: <https://orcid.org/0000-0001-5248-9192. http://lattes.cnpq.br/77804293749333352>. E-mail: dboleao@gmail.com.
} 
Portanto, esse se configura como um estudo de revisão bibliográfico, onde foram utilizados os cadernos disponibilizados pelo MEC que subsidiaram a formação continuada dos professores na educação infantil que foram produzidos pelo projeto Leitura e escrita na educação infantil para discutir acerca dos dilemas e os discursos dirigidos aos professores nesse material sobre a ação pedagógica nessa etapa de ensino.

Buscamos, assim, contribuir, com as discussões e reflexões dos professores que atuam na Educação Infantil, acerca das políticas curriculares que se tecem. Sendo imperativo os professores realizem uma análise profunda sobre do material sugerido para a formação continuada, bem como sobre as políticas educacional e curriculares que estão sendo instituída na Educação Básica.

\section{PACTO NACIONAL PELA ALFABETIZAÇÃO NA IDADE CERTA: UM BREVE HISTÓRICO}

A meta cinco do Plano Nacional de Educação (PNE) $)^{1}$ descreve que a alfabetização de todas as crianças deve ocorrer, no máximo, até o final do $3^{\circ}$ ano do Ensino Fundamental. Além disso, em um terceiro bloco de metas, o PNE apresenta a valorização dos profissionais da educação como estratégia para o cumprimento de metas como a referida anteriormente, acerca da alfabetização dos educandos.

O PNE deve ser a base para a construção dos planos do distrito, dos estados e munícipios. Estes, por sua vez, têm o compromisso de prever recurso orçamentário para a execução desses planos, após aprovação por lei. Diante disso, é fundamental que suas metas sejam acompanhadas pelas escolas, pelas secretarias dos municípios e pela secretaria do estado. Entende-se, também, que as diferentes esferas governamentais precisam trabalhar de forma articulada, alinhando suas metas ao PNE e favorecendo a consolidação de acordos que facilitem as políticas públicas referentes à educação.

Desta forma, o Pacto Nacional pela Alfabetização na Idade Certa apoia-se nas referidas metas, tendo sido criado a partir de uma política educacional que iniciou em 2012, quando as Universidades passaram a constituir equipes de formação. Entretanto, sua implementação ocorreu em 2013, abrangendo todas as regiões do país, em conjunto com os municípios que aderiram às atuações desse programa (BRASIL, 2014). Essa ação articulada entre o Governo Federal, Distrito

\footnotetext{
${ }^{1}$ O Plano Nacional de Educação teve sua configuração modificada a partir da Emenda Constitucional no 59/2009, sendo instituída a sua obrigatoriedade e duração decenal. Esse plano tem por objetivo articular o sistema nacional de educação em regime colaborativo, definindo diretrizes, objetivos, metas e estratégias a serem implementados, visando à manutenção e ao desenvolvimento do ensino nos seus diversos níveis, etapas e modalidades. (BRASIL, 2014).
} 
Federal, governos estaduais e municipais configura-se em um compromisso com a plena alfabetização das crianças até o final do terceiro ano do Ensino Fundamental e está apoiada em quatro eixos de atuação: (a) formação continuada para professores alfabetizadores; (b) disponibilização de materiais didáticos; (c) avaliações sistemáticas e gestão, controle e; (d) mobilização social (BRASIL, 2014).

O PNAIC, em seu primeiro ano, priorizou a discussão referente à Língua Portuguesa e enfatizou o currículo no processo de alfabetização, que se apresentou como um currículo inclusivo, onde o educando tem o direito de ser alfabetizado. No segundo ano, a formação decorreu em torno da matemática e, a partir de 2015, se ampliou para as demais áreas do conhecimento, pensando nessas áreas de maneira integrada - afinal, segundo a proposta do Programa, as crianças necessitam de uma educação integral. Portanto, a formação continuada ofertada pelo Programa tem a "tarefa de ampliar as discussões sobre a alfabetização na perspectiva do letramento, numa abordagem interdisciplinar" (BRASIL, 2015b, p. 7).

No caso específico da alfabetização em Língua Portuguesa, o docente precisa compreender a língua que pretende ensinar, ou seja, dominar as regras gráficas, ortográficas e gramaticais dessa língua e perceber que "alfabetização é o processo em que as crianças aprendem não somente a ler e a escrever, mas também a falar e a escutar em diferentes contextos sociais; e que a leitura, a escrita, a fala e a escuta representam meios de apropriação de conhecimentos relevantes à vida" (BRASIL, 2015b, p. 7).

Nesse sentido, a proposta do PNAIC para a Língua Portuguesa está pautada na aprendizagem do sistema de escrita alfabética, objetivando que o docente compreenda que o alfabeto é um sistema notacional e não apenas um código. Com esse entendimento, se torna necessário uma nova maneira de analisar como o educando compreende as palavras.

No que se refere à alfabetização na Matemática, o PNAIC segue uma perspectiva de letramento, onde essa pode ser compreendida como um instrumento para a leitura de mundo, a qual objetiva superar a simples decodificação dos números e a resolução das quatro operações básicas, proporcionando ao educando uma aprendizagem matemática pautada no lúdico, evidenciando as necessidades dessa faixa etária, respeitando seus modos de pensar e sua lógica no processo da construção de conhecimento (BRASIL, 2014).

Na última coletânea de Cadernos PNAIC 2015/2016, a proposta foi considerar os aspectos essenciais para a alfabetização nas diferentes áreas de conhecimento, através da retomada de conceitos importantes da linguagem e da matemática, propondo a integração dos saberes, 
possibilitando a discussão referente à interdisciplinaridade, ciclo de alfabetização, diversidade, currículo inclusivo, entre outros.

No ano de 2016 e primeiros meses de 2017, o Programa apresentou uma estrutura denominada PNAIC em Ação, dando continuidade ao trabalho com os cadernos mencionados anteriormente. Além disso, essa proposta do programa fortaleceu a atuação do Comitê Gestor, ${ }^{2}$ que contou com a participação de representantes da Secretaria de Estado da Educação, da União dos Dirigentes Municipais e das Instituições de Ensino Superior, tendo como principal atribuição as tratativas referentes à gestão, ao planejamento e à execução do Programa.

No segundo semestre de 2017, o Ministério da Educação (MEC) e a Secretaria da Educação Básica (SEB) apresentaram uma nova versão do PNAIC, onde se apresenta uma perspectiva de ampliar a alfabetização e como isso propõe a participação de professores e coordenadores pedagógicos que atuam na Educação Infantil e de Articulares e Mediadores do Programa Novo Mais Educação.

A partir de 2017, analisando a experiência adquirida, algumas inovações foram implementadas. O PNAIC passa a compor uma política educacional sistêmica que parte de uma perspectiva ampliada de alfabetização, trabalhando a Alfabetização na Idade Certa, a melhoria da aprendizagem em Língua Portuguesa e Matemática no Ensino Fundamental, bem como a inclusão da Educação Infantil e o Programa Novo Mais Educação. Optou-se por adotar uma estratégia descentralizada para atender à diversidade de arranjos federativos, além de valorizar experiências exitosas e inspiradoras. (BRASIL, 2017b, p.5).

Para orientar a participação da Educação Infantil nas formações do Programa, o MEC apresentou os Cadernos produzidos pelo projeto Leitura e Escrita na Educação infantil, escritos pela equipe de professores da Universidade Federal de Minas Gerais (UFMG), da Universidade Federal do Rio de Janeiro (UFRJ) e da Universidade Federal do Estado do Rio de Janeiro (UNIRIO), em parceria com os profissionais da Coordenação Geral da Educação Infantil da SEB.

Tendo em vista o histórico do Programa, as mudanças propostas pelo MEC ao longo de sua execução e as discussões realizadas no curso de pós-graduação Mestrado Profissional em Política Públicas e Gestão Educacional, surge a necessidade do entrelaçamento de conceitos, tencionando a

\footnotetext{
${ }^{2}$ Com o objetivo de fortalecer as estruturas de gestão estadual e municipal, foram incluídos na equipe de gestão um representante da Undime e um coordenador regional para colaborar com a articulação entre as redes. Os coordenadores Undime, estadual e de formação formaram o Comitê Gestor Estadual para Alfabetização e Letramento, responsáveis pela organização, funcionamento e acompanhamento das ações do programa em seus respectivos estados. (BRASIL, 2017b)
} 
possível compreensão dos caminhos propostos por esse Programa para a Educação Infantil. Para isso, é imperativo que se apresente um entendimento referente à infância, à criança e essa etapa inicial da Educação Básica, o que se tece nos capítulos seguintes.

\section{CRIANÇA E INFÂNCIA: COMPREENDENDO CONCEITOS AO LONGO DA HISTÓRIA}

A expressão "infância" foi se constituindo ao longo da história da humanidade, desde que o homem se organiza em um meio social e, por consequência, sofre diversas transformações ao longo da evolução das diferentes formas sociais e momentos dessa organização humana em sociedade.

Philippe Ariès (2014) definiu duas concepções que caracterizam a infância: a primeira se refere à sociedade tradicional ou pré-industrial e a outra criada a partir dos séculos XV e XVI. Segundo Ariès, nas sociedades tradicionais,

A duração da infância era reduzida a seu período mais frágil, enquanto o filhote do homem ainda não conseguia basear-se, a criança então, mal adquiria algum desembaraço físico, era logo misturada ao adulto, e participava de seus trabalhos e jogos. De criancinha pequena, ela se transformava imediatamente em homem jovem, sem passar pelas etapas da juventude (...). A transmissão dos valores e dos conhecimentos, e de modo mais geral, a socialização da criança, não era, portanto, nem asseguradas nem controladas pela família. (ARIÈS, 2014, p. ix).

Nas sociedades tradicionais descritas pelo autor, a criança era vista como um pequeno adulto e a adolescência não era considerada como uma etapa entre a infância e a juventude, como nos é apresentado a partir do século XX; essa etapa simplesmente não tinha espaço. Baseado em fontes materiais (efigie funerárias e escritas em túmulos) e documentos escritos, o autor demonstra que durante a Idade Média as crianças eram indivíduos anônimos, onde seus nomes sequer eram escritos nos túmulos infantis. (ARIÈS, 2014)

Durante o século XIV, as idades da vida não correspondiam somente à idade biológica, mas eram associadas às funções que eram desempenhadas. Ou seja, na primeira idade, as crianças brincavam. Após, vinha a idade da escola, onde os meninos aprendiam a ler e as meninas a fiar. Posteriormente, "as idades do amor e dos esportes, da corte e da cavalaria". E, por último, para o homem, a idade da guerra, antes das idades "sedentárias”. (ARIÈS, 2014, p. 9).

Rousseau (2004) descreve a criança do século XVIII como um indivíduo que nasce fraco, precisando de força, carente de tudo, necessitando de assistência; e estúpido, precisando de juízo. 
Além disso, para Rousseau (2004, p. 9), “o que o recém-nascido não tem ao nascer lhe é dado através da educação, que pode vir da natureza, do homem ou das coisas”.

Em vista disso, entende-se que a criança não chegou a sair de um anonimato até o século XVII, quando uma mudança considerável aconteceu: a escola passou a assumir a tarefa de educar. Isso significa que a criança deixou de conviver exclusivamente com adultos e aprender a vida diretamente com eles e passou a manter distância numa "espécie de quarentena, antes de ser solta no mundo" (ARIÈS, 2014, p. x). Essa quarentena é entendida por Ariès (2014) como a escola, iniciando assim um longo "processo de enclausuramento" das crianças, o qual, segundo o autor, dáse o nome de "escolarização".

A partir do século XIX e XX, ainda segundo o autor, a família começou a acompanhar os estudos de seus filhos, organizando-se em torno da criança e atribuindo-lhe importância.

Nesse sentido, acerca da participação das crianças na escola, é necessário destacar o pensamento dos intelectuais humanistas do século XVI, destacado por Boto (2002, p. 15), os quais “[...] rejeitavam enfaticamente a alternativa escolar, quase como se esta, por si, representasse um desdobramento da escolástica [...]”, o que é explicado pelos autores com a afirmação de que é importante o "[...] reconhecimento da natureza da criança no âmbito de seu processo educativo, eles supunham que a escolarização seria, por definição, incapaz de apreensão da índole própria da criança [...]". Assim, tais intelectuais buscavam uma pedagogia voltada à humanidade, que se corresponde a um modelo de ensino mais eficaz.

Pode-se destacar os colégios Jesuíticos que, de alguma maneira, perpetuaram os ideais pedagógicos reivindicados pela Renascença; porém, para realizar o seu propósito de catequização, "precisaram esvaziar algumas obras de escritores antigos de seu conteúdo positivo; isto é, esvaziálas de seu paganismo" (BOTO, 2002, p. 24). É nesse cenário que voltamos nosso olhar para as crianças que viviam no Brasil, pois aqui a infância também era considerada um tempo sem muita personalidade, um momento de transição. Tal situação é explicada por Galeno (IN: DEL PRIORE, 2000, p. 84):

A "puerícia" tinha a qualidade de ser quente e úmida e durava do nascimento até os 14 anos. A segunda idade, chamada adolescência, cuja qualidade era ser "quente e seca", perdurava dos 14 aos 25 anos. Na lógica de Galeno, o que hoje chamamos infância correspondia aproximativamente à puerícia. Esta por seu turno, dividia-se em três momentos que variam de acordo com a condição social de pais e filhos. O primeiro ia até o final da amamentação, ou seja, findava por volta dos três ou quatro anos. No segundo, que ia até os sete anos, crianças cresciam à sombra dos pais, acompanhando- 
os nas tarefas do dia a dia. Daí em diante, as crianças iam trabalhar, desenvolvendo pequenas atividades, ou estudavam a domicílio, com preceptores ou na rede pública, por meio das escolas régias, criadas na segunda metade do século XVIII, ou, ainda aprendiam algum ofício, tornando-se "aprendizes".

Dessa forma, entende-se que a formação da criança ocorria na presença de seus pais ou no acompanhamento pedagógico, que tinha por objetivo transformá-la em um indivíduo responsável. Del Priore (2000) apresenta em sua discussão que pouco a pouco a educação e os médicos conseguiram ir aperfeiçoando a criança no Brasil colonial, pois por mais que se prestasse atenção à sobrevivência das crianças, médicos, educadores e os pais preocupavam-se em adestrá-la, buscando prepará-las para assumir responsabilidades.

As primeiras instituições brasileiras responsáveis pela educação da criança pequena surgiram no país em 1890, voltadas aos cuidados com a higiene dos pequenos, objetivando suprir os cuidados necessários para a sobrevivência. Segundo Kuhlmann Jr. (1998) as propostas educacionais destinadas principalmente às classes populares, constituíam-se basicamente de um caráter compensatório, pautado em uma tradição de atendimento a bebês e crianças pequenas na creches e pré-escolas, enraizados na perspectiva assistencialista e escolarizante da infância.

Esse cenário só sofreu modificações após importantes lutas sobre a obrigatoriedade da oferta da educação pública em creches e pré-escolas, nos anos 1980, firmando-se a partir daí a garantia dos direitos das crianças e de suas famílias no que se referia a frequência de espaços públicos e gratuitos próprios a educação na infância. Esse movimento orientou os documentos oficiais das décadas seguintes, evidenciando que na Educação Infantil é necessário priorizar os seguintes eixos: cuidar, educar e brincar, contestando então a proposta anterior, assistencialista e escolarizante ofertada nas creches e pré-escolas.

Assim, as Diretrizes Curriculares Nacionais para Educação Infantil, instituído pelo Ministério da Educação em 2009, traz o reconhecimento dos direitos das crianças e esclarece o dever do Estado no que tange a garantia de oferta de vagas para creches e pré-escolas. Além de apresentar no Art. $5^{\circ}$ da Resolução n ${ }^{\circ}$ 5, de 17 de dezembro de 2009, a obrigatoriedade de matrícula na Educação Infantil de crianças que completam 4 e 5 anos.

Ainda, no art. 11 da referida resolução está estabelecido que a transição para o Ensino Fundamental, etapa subsequente a Educação Infantil, na organização da Educação Básica no Brasil, “a proposta pedagógica deve prever formas para garantir a continuidade no processo de 
aprendizagem e desenvolvimento das crianças, respeitando as especificidades etária sem antecipação de conteúdos” que serão trabalhados na próxima etapa.

Nesse sentido, a Base Nacional Comum Curricular (BNCC), posta em vigor em 2017, apresenta a seguinte concepção acerca da criança e da ação pedagógica destinada a ação educativa na Educação infantil.

Essa concepção de criança como ser que observa, questiona, levanta hipóteses, conclui, faz julgamentos e assimila valores e que constrói conhecimentos e se apropria do conhecimento sistematizado por meio da ação e nas interações com o mundo físico e social não deve resultar no confinamento dessas aprendizagens a um processo de desenvolvimento natural ou espontâneo. Ao contrário, impõe a necessidade de imprimir intencionalidade educativa às práticas pedagógicas na Educação Infantil, tanto na creche quanto na pré-escola. (BRASIL, 2017, p. 34).

Assim, a criança precisa ser desafiada através de experiências que permitam a elas conhecer a si mesmo e ao outro e de conhecer e compreender as relações com a natureza, com a cultura e com a produção científica, que se traduzem nas práticas de cuidados pessoais, nas brincadeiras, nas experimentações com materiais variados, e na aproximação com a literatura voltada a essa faixa etária.

Desse modo, a BNCC orienta o professor a "refletir, selecionar, organizar, planejar, mediar e monitorar o conjunto das práticas que promovam a garantia dos direitos e o desenvolvimento das crianças.

Por fim, entende-se que as crianças, hoje, necessitam de desafios, interações com os adultos e com as outras crianças, além de atividades que promovam a construção de conhecimentos e possibilitem seu desenvolvimento. Podemos dizer que garantir o direito de aprendizagem e desenvolvimento da criança, relaciona-se com a garantia de que essa possa experimentar, interagir e brincar nos espaços escolares, sendo a escola um espaço prazeroso de conhecimento e desenvolvimento.

Por fim, colaborando com a compreensão dos direitos de aprendizagem e desenvolvimento infantil, torna-se necessário revisitar autores que abordam os marcos legais que levaram a educação destinada aos pequenos a integrar a Educação Básica no Brasil e se tornar um espaço onde através da brincadeira é possível educar. 


\section{A EDUCAÇÃO INFANTIL E OS MARCOS LEGAIS}

A partir do final da década de 1970, no Brasil, muitos estudiosos iniciaram sua árdua luta pela implementação de creches e pré-escolas que respeitem os direitos das crianças e de suas famílias. Assim, a Constituição de 1988 caracteriza as instituições de Educação Infantil como parte dos deveres do Estado, assegurando que a educação é um direito de todos, postulando políticas sociais e educacionais, sob uma orientação universalizante. Na Constituição Federal é garantida a obrigatoriedade de atendimento em creche e pré-escola para as crianças de zero a seis anos de idade, conforme inciso IV do artigo 208.

Os direitos das crianças de zero a seis anos vão ganhando reconhecimento e força a partir daí. Na sequência, temos a consolidação do Estatuto da Criança e do Adolescente, a Lei de Diretrizes e Bases da Educação (Lei 9.394/96), as Diretrizes Curriculares para a Educação Infantil e o Plano Nacional de Educação - documentos que asseguram a atenção do Estado acerca das necessidades das crianças em etapa inicial da Educação Básica.

Desse modo, a Educação Infantil configura-se como matéria de responsabilidade dos sistemas de ensino. Cabe salientar que poderiam ter ocorrido outros encaminhamentos que a conduzissem aos cuidados da assistência social, porém o Brasil optou por deixar a cargo do atendimento educacional a criança dessa faixa etária. Assim, foi proposta uma articulação entre as dimensões sociais, políticas e administrativas; entretanto, tal ação só ocorreu após a expressão dos movimentos sociais de lutas dos diferentes setores da sociedade civil em torno de programas de atenção à criança. Essa perspectiva pedagógica passa a considerar a criança com um ser social, histórico, que pertence a uma sociedade. (KUHLMANN Jr., 2015).

Com o propósito de compreender um pouco mais sobre os marcos legais e regulatórios citados anteriormente, optou-se por comentar, a partir daqui cada um deles.

Inicia-se discorrendo um pouco mais sobre o Estatuto da Criança e do Adolescente (ECA), que se configura como um marco legal e regulatório, o qual assegura os direitos da criança e do adolescente através da Lei 8.069, de 13 de julho de 1990. Tal documento aponta que os munícipios passaram a ter responsabilidade pelos direitos da infância e adolescência, através da criação de Conselhos Municipais, do Fundo Municipal e do Conselho Tutelar. O ECA apresenta, também, uma diferenciação entre a criança e a adolescência, estabelecendo que o indivíduo na faixa etária de zero a doze anos é considerado criança e, na faixa etária de doze a dezoito anos, é considerado adolescente. 
A Lei de Diretrizes e Bases da Educação, (Lei 9.394/96), por sua vez, define a educação infantil como primeira etapa da educação básica e assegura o direito de crianças nessa faixa etária serem atendidas gratuitamente nas creches e pré-escolas, reconhecendo que a educação é um direito da criança e que essa é um sujeito de direito e não mais de tutela, como era mencionado em legislações anteriores.

Ao tratar de manutenção e desenvolvimento da Educação Infantil, uma das mudanças significativas que ocorreram sobre esses aspectos configura-se na substituição do Fundo de Manutenção e Desenvolvimento do Ensino Fundamental e de Valorização do Magistério (FUNDEF) pelo Fundo de Manutenção e Desenvolvimento da Educação Básica (FUNDEB) que, segundo Vieira (2009, p. 61), "promove a distribuição dos recursos com base no número de alunos da Educação Básica pública (creches, pré-escola, ensino fundamental, ensino médio, educação especial e educação de jovens e adultos)". Assim, entende-se que os recursos do FUNDEB devem ser direcionados para que a política voltada à educação infantil respeite os direitos fundamentais da criança pequena.

O Plano Nacional de Educação (PNE), promulgado em 2001, estabelecia metas para o atendimento a $60 \%$ das crianças de 4 a 6 anos e a $30 \%$ daquelas de 0 a 3 anos de idade, no prazo de cinco anos e, até o final da década, alcançar a meta de $50 \%$ das crianças de 0 a 3 anos e $80 \%$ daquelas de 4 a 5 anos (BRASIL, 2001). Essa última demandou um movimento significativo dos munícipios a fim de conseguir cumprir o estabelecido; entretanto, não foi possível que atingisse a completude de tal meta, sendo novamente projetada no PNE 2014 - 2024 em sua meta 1, apresentada da seguinte forma: "Universalizar, até 2016, a educação infantil na pré-escola para as crianças de 4 a 5 anos de idade e ampliar a oferta de educação infantil em creches de forma a atender, no mínimo, $50 \%$ das crianças de até 3 anos [...]”.

A Lei 11.274, de 06 de fevereiro de 2006, instituiu o ensino fundamental de nove anos de duração, bem como a inclusão de crianças de seis anos de idade nessa etapa da Educação Básica. Assim, as crianças com seis anos completos até 31 de março, passaram a frequentar o primeiro ano do Ensino Fundamental, mas conservou-se a faixa etária de zero a cinco anos e onze meses na Educação Infantil até a conclusão da pré-escola.

As Diretrizes Curriculares Nacionais para a Educação Infantil, o próximo marco regulatório a ser comentado, fixadas a partir da Resolução $n^{\circ}$ 5, de 17 de dezembro de 2009, foram também um marco legal significativo para a Educação Infantil. Tais Diretrizes orientam sobre o currículo na educação infantil, considerando a criança como centro do planejamento curricular, sendo um sujeito 
histórico e de direitos. Em seus treze artigos, garantem o direito à educação, gratuita, de qualidade e pública a todas as crianças de zero a cinco anos de idade, sendo a linha básica que orienta o caminho que se pretende seguir para essa etapa da Educação Básica.

Foi através da Lei 12.796, de 4 de abril de 2013, que a obrigatoriedade de crianças com idade de quatro a dezessete anos de idade passou a incorporar a Lei de Diretrizes e Bases da Educação, onde a Educação Básica foi organizada em pré-escola, ensino fundamental e ensino médio, sendo assegurada, portanto, a gratuidade de oferta da educação infantil às crianças de até cinco anos de idade. Nessa legislação, ainda, se encontra a seguinte redação: “A educação infantil, primeira etapa da educação básica, tem como finalidade o desenvolvimento integral da criança de até 5 (cinco) anos, em seus aspectos físico, psicológico, intelectual e social, complementando a ação da família e da comunidade" (BRASIL, 2013, art. 29).

Diante disso, no ano de 2015, iniciou-se no Brasil um movimento pela elaboração de uma Base Nacional Comum Curricular para toda a Educação Básica, onde a Educação Infantil foi contemplada e igualmente citada como a primeira etapa da Educação Básica. Esse documento encontra-se homologado pelo Conselho Nacional de Educação (CNE) e apresenta em sua constituição os diretos de aprendizagem das crianças nessa etapa da Educação Básica, sendo necessário salientar ainda que tal documento foi construído com a participação da população brasileira e, antes de sua homologação, foram elaboradas três versões da Base.

Sobre a Educação Infantil, podemos dizer que a segunda versão da Base Nacional Comum Curricular - BNCC segue as Diretrizes Curriculares Nacionais e traz o seguinte texto:

O posicionamento em relação aos processos pedagógicos na Educação Infantil parte da concepção de que a construção de conhecimentos pelas crianças nas unidades de Educação Infantil, urbanas e do campo, efetiva-se pela sua participação em diferentes práticas cotidianas nas quais interagem com parceiros adultos e companheiros de idade. (BRASIL, 2016, p. 17).

$\mathrm{Na} \mathrm{BNCC}$, conforme apresentado anteriormente, a educação infantil é evidenciada como a primeira etapa da educação básica, devendo assegurar os direitos de aprendizagem e desenvolvimento da criança, quais sejam: Direito de conviver, brincar, participar, explorar, expressar e conhecer-se; tudo isso é possível através dos campos de experiência: $\mathrm{O}$ eu, o outro e o nós; Corpo, gestos e movimentos; Traços, sons, cores e formas; Escuta, fala, pensamento e imaginação; Espaços, tempos, quantidades, relações e transformações, nos quais as crianças podem aprender e se desenvolver. (BRASIL, 2017a). 
Há muitos aspectos referentes aos marcos regulatórios que são significativos ao se tratar de Educação Infantil, bem como ao entendimento que se tem hoje acerca da criança e da infância; porém, aqui apresentou-se apenas alguns desses, a fim de conduzir a reflexão sobre as políticas educacionais destinadas à educação infantil que se consolidam na atualidade.

Diante desse cenário, podemos dizer que a Educação Infantil tem sido pensada como primeira etapa da Educação Básica e, a partir daí, decorrem as políticas educacionais que se tecem acerca dos aspectos educativos destinados às crianças dessa faixa etária. A partir daí buscaremos discutir a inserção dessa etapa no Programa Pacto Nacional pela Alfabetização na Idade Certa.

\section{A EDUCAÇÃO INFANTIL E O PNAIC}

Em capítulo anterior, foi mencionado que o Pacto Nacional pela Alfabetização na Idade Certa - PNAIC configura-se como uma política curricular que apresenta em um de seus eixos a formação continuada de professores, o qual visa possibilitar permanentemente a construção de saberes/fazeres docentes, a partir das necessidades e desafios que o ensino apresenta.

Deste modo, de acordo com o Documento Orientador escrito pela Secretaria de Educação Básica do MEC em 2017, o qual objetiva nortear as ações desse programa, o PNAIC "passa a compor uma política educacional sistêmica que parte de um perspectiva ampliada de alfabetização", com o propósito de melhorar a aprendizagem em Língua Portuguesa e Matemática, a partir dos resultados obtidos pelas avaliações realizadas pelo Sistema de Avaliação da Educação Básica (SAEB), por meio da prova Avaliação Nacional da Alfabetização (ANA). A partir daí se propõe a “inclusão da Educação Infantil garantindo as perspectivas e as especificidades do trabalho de leitura e escrita com as crianças". (BRASIL, 2017b).

Dessa forma, entende-se que ao professor de pré-escola caberá a ação de desenvolver o trabalho com a leitura e escrita, em creches e pré-escolas. O perfil desse profissional é apresentado no documento orientador, junto ao professor alfabetizador de $1^{\circ}$ a $3^{\circ}$ ano, com a seguinte descrição:

O Professor Alfabetizador/Pré-escola deverá colaborar com as discussões pedagógicas relacionadas aos materiais e à formação e apontar as dificuldades que enfrenta, visando à sua superação e, também, planejar e executar ações pedagógicas em sua turma, utilizando os recursos didáticos selecionados pela rede e outros que atendam diretamente à sua necessidade de aperfeiçoamento e às dificuldades de aprendizagem do aluno. Para isso, poderá compartilhar com o coordenador pedagógico e outros colegas materiais desenvolvidos, boas práticas e conhecimentos adquiridos. O professor é responsável por aplicar as avaliações diagnósticas aos alunos de sua turma 
e buscar orientação de formadores e colegas se encontrar dificuldades. A partir do diagnóstico, o professor deverá acompanhar o progresso da aprendizagem de cada aluno de sua turma, bem como organizar atividades para que todas as crianças possam evoluir no seu processo de aprendizagem. Outra atribuição que contribui para essa evolução é organizar atividades diversificadas que contemplem diferentes níveis de alfabetização, atendendo a todos os alunos e buscando que todos alcancem um patamar adequado de aprendizagem ao final de cada mês/semestre/ano. [...] (BRASIL,2017b).

Tendo em vista as questões apontadas no Documento Orientador e as mudanças ocorridas na versão homologada da BNCC, entende-se que a configuração do PNAIC se apoia nessa mudança, elencando a oralidade e a escrita como integrante do processo pedagógico na Educação Infantil.

Esses cadernos estão pautados nas Diretrizes Curriculares Nacionais para a Educação Infantil, tendo como eixos orientadores a interação e a brincadeira, evidenciando que as práticas pedagógicas que compõem a proposta curricular para esta etapa da educação básica devem garantir à criança um vasto campo de experiências, sendo apresentado no caderno 0 (zero) dois aspectos que precisam ser considerados em relação ao que esses campos de experiência devem proporcionar:

[...] II. favoreçam a imersão das crianças nas diferentes linguagens e o progressivo domínio por elas de vários gêneros e formas de expressão: gestual, verbal, plástica, dramática e musical; III - possibilitem às crianças experiências de narrativas, de apreciação e interação com a linguagem oral e escrita, e convívio com diferentes suportes e gêneros textuais orais e escritos; [...].

Assim, na tentativa de efetivação de práticas pautadas nos campos de experiências descritos na BNCC, a etapa Educação Infantil passa a integrar o Programa Pacto Nacional pela alfabetização na Idade Certa, o que nos conduz nesse momento a uma reflexão pautada no histórico de lutas dos diversos grupos a favor de um atendimento de qualidade para as crianças que compõem essa etapa. Tal reflexão perpassa o sentido de repensar as estruturas físicas, as formas de avaliação, a construção dos projetos pedagógicos, a valorização docente e a formação adequada para que esses possam oferecer um atendimento educacional de qualidade para os bebês e para as crianças pequenas.

Desse modo, entende-se que a formação continuada para os professores da educação infantil deve permear o reconhecimento dos direitos das crianças nessa etapa de ensino, através de ações pedagógicas que favoreçam o desenvolvimento da linguagem oral e escrita, sem antecipar o que é próprio do Ensino Fundamental, mas sim, tecer articulações entre os conhecimentos da cultura 
escrita e das diversas linguagens que constituem o mundo onde essas crianças estão inseridas, sempre valorizando o lúdico, as brincadeiras e as culturas infantis.

\section{CONSIDERAÇÕES FINAIS}

Por todos os aspectos apresentado ao longo desse artigo, entendemos que ao pensarmos na Educação Infantil, considerando a criança, seu desenvolvimento e a construção de conhecimento, precisamos estar atentos e dar condições para que essa se desenvolva plenamente em seus aspectos físico, social, cognitivo e afetivo, oportunizando o que é próprio de sua faixa etária.

Partindo do diálogo que pode ser estabelecido com os autores dos cadernos produzidos pelo projeto Leitura e Escrita na Educação infantil, os professores podem resgatar a singularidade de significação e de inserção social da criança, compreendendo que o currículo na educação infantil precisa ser organizado com foco na ação das crianças, a partir de diferentes linguagens - inclusive da leitura e da escrita.

Durante os encontros do Programa no Eixo da Educação Infantil, as Instituições de Ensino Superior responsáveis pela execução das formações evidenciaram o trabalho com a linguagem oral e escrita, em creches e pré-escolas, bem como a importância do docente como agente de promoção do acesso da criança à cultura, e, em especial, à leitura escrita, por meio da manipulação de diversos livros, poemas, desenhos animados, jogos, imagens, sons desde os primeiros anos de vida, possibilitando a ampliação das experiências infantis nos ambientes escolares.

Por fim, torna-se indispensável esclarecer que, mesmo sendo exposta aqui uma ideia do que se compreende até o presente momento sobre a inserção da Educação Infantil no Programa Pacto Nacional pela Alfabetização na Idade, muito ainda precisa ser refletido e discutido, sendo imperativo a realização de uma análise mais profunda acerca do material sugerido como subsídio para a formação dos professores da pré-escola, bem como sobre a política educacional instituída para a Educação Básica. 


\section{REFERÊNCIAS}

ARIÈS, Philipe. História social da criança e da família. Trad. Dora Flaksman. 2. ed. Rio de Janeiro: LTC, 2014.

BOTO, Carlota. O Desencantamento da Criança: entre a Renascença e o Século das Luzes. In: FREITAS, M. C.; KUHLMANN JUNIOR, M. (Orgs.). Os Intelectuais na História da Infância. São Paulo: Cortez. 2002. p. 11-60

BRASIL, Constituição da República Federativa do Brasil. Diário Oficial da União. Brasília: Congresso Nacional, 05 out. 1988. Anexo. Disponível em: <http://www.planalto.gov.br/ccivil_03/constituicao/constituicaocompilado.htm> Acesso em: 07 $\operatorname{dez} 2017$.

. Lei 9.394, de 20 de dezembro de 1996. Estabelece as diretrizes e bases da educação nacional. Diário Oficial da União. Brasília: Poder Legislativo, 23 dez. 1996, sec. I, n. 248, p. 27.833. Disponível em: <http://www. planalto.gov.br/ccivil_03/leis/L9394.htm> Acesso em: 07 dez 2017.

. Lei 11.274. Estabelece a duração de 9 (nove) anos para o ensino fundamental. Diário Oficial da União. Brasília: Poder Legislativo, 07 fev. 2006, sec. I. Disponível em: <http://www.planalto.gov.br/ccivil_03/_ato20042006/2006/lei/l11274.htm> Acesso em: 07 dez 2017.

. Lei 12.796. Estabelece as diretrizes e bases da educação nacional, para dispor sobre a formação dos profissionais da educação. Diário Oficial da União. Brasília: Poder Legislativo, 05 maio 2013. Disponível em: <http://www.planalto.gov.br/ccivil_03/_ato2011-2014/2013/lei/112796.htm> Acesso em: 07 dez 2017.

. Plano Nacional de Educação: Lei 10.172/2001. Aprova o Plano Nacional de Educação. Diário Oficial da União. Brasília: Poder Legislativo, 10 jan. 2001. Disponível em: 〈http://www.planalto.gov.br/ccivil_03/leis/leis_2001/ 110172.htm> Acesso em: $08 \mathrm{dez} 2001$.

Resolução $\mathbf{n}^{\mathbf{0}}$ 5, de 17 dez. 2009. Disponível em: < http://www.siteal.iipe.unesco.org/sites/default/files/bra_educacion_infantil.pdf > Acesso em: $08 \mathrm{dez} 2017$.

. Lei 13.005/2014. de 25 de junho de 2014. Aprova o Plano Nacional de Educação - PNE. Diário Oficial da União. Poder Legislativo, Brasília, 26 jun. 2014, edição extra, p. 1. Disponível em: 〈http://www.planalto.gov.br/ccivil_03/_ato20112014/2014/lei/113005.htm>Acesso em 08 dez 2017.

. Base Nacional Comum Curricular. Proposta Preliminar. Segunda Versão. Revista. Brasília: MEC, 2016.

Base Nacional Comum Curricular. Proposta Preliminar. Terceira Versão. Revista. Brasília: MEC, 2017 a. Disponível em: http://basenacionalcomum.mec.gov.br/images/pdf/3_BNCC-Final_Infantil.pdf>. Acesso em 11 dez 2017.

, MEC; Secretaria de Educação Básica; Diretoria de Apoio à Gestão Educacional. Pacto Nacional pela Alfabetização na Idade Certa: Apresentação. Brasília: MEC, SEB, 2014.

; MEC; Secretaria de Educação Básica; Diretoria de Apoio à Gestão Educacional. Pacto Nacional pela Alfabetização

na Idade Certa: Interdisciplinaridade no ciclo de alfabetização. Caderno de Apresentação. Brasília: MEC, SEB, $2015 a$.

; MEC; Secretaria de Educação Básica; Diretoria de Apoio à Gestão Educacional. Pacto Nacional pela Alfabetização na Idade Certa -A oralidade, a leitura e a escrita no ciclo de alfabetização. Caderno 5. Brasília: MEC, SEB, $2015 b$.

; MEC; Secretaria de Educação Básica; Diretoria de Apoio à Gestão Educacional. Caderno de Apresentação: Coleção Leitura e escrita na educação infantil; Brasília: MEC/SEB, 2016.

, MEC; Secretaria de Educação Básica; Diretoria de Apoio à Gestão Educacional. Pacto Nacional pela Alfabetização na Idade Certa: Documento Orientador 2017. Brasília: MEC/SEB, $2017 \mathrm{~b}$.

, MEC; Secretaria de Educação Básica. Base Nacional Comum Curricular. Brasília: MEC, SEB, 2017. Disponível em: http://basenacionalcomum.mec.gov.br/abase/\#infantil. Acesso em: 04 jan. 2019.

DEL PRIORE, M. O cotidiano da criança livre no Brasil: entre a colônia e o império. DEL

PRIORE, M. (Org.). História das crianças no Brasil. São Paulo: Contexto, 2000.

HEYWOOD, Colin. Uma História da Infância: da Idade Média à época contemporânea no Ocidente. - POA: Artmed, 2004.

KUHLMANN JR. Educando a Infância Brasileira. In: LOPES. E.M.T.; FARIA FILHO, L.M.; VEIGA, G.G. (Org.). 500 Anos de Educação no Brasil. Belo Horizonte: Autêntica, 2007.

ROUSSEAU, J.J. Emilio ou Da Educação. 3. ed. São Paulo: Martins Fontes, 2004.

VIEIRA, Sofia Lerche. Educação básica política e gestão da escola. Brasília: Liber Livro, 2009. 


\section{RESUMO}

Entre 2017/2018, o Ministério da Educação incluiu a etapa, Educação Infantil, no Programa Pacto Nacional pela Alfabetização na Idade Certa - PNAIC -, conduzindo a reflexão sobre temáticas referentes às políticas curriculares e formação de professores que atuam nesse contexto. O objetivo deste estudo bibliográfico é discutir a implementação desse programa na Educação Infantil. Inicialmente, realizamos um resgate histórico sobre o PNAIC. Posteriormente, apresentamos a concepção de criança e infância, a partir dos conceitos que se constituíram ao longo da história no Brasil. Após, apresentamos uma análise dos marcos que sustentam a ação pedagógica na Educação Infantil. Por fim, realizamos uma análise da proposta construída, na tentativa de elucidar a sua repercussão nas práticas educativas.

Palavras-chave: Pacto Nacional pela Alfabetização na Idade Certa. Educação Infantil. Alfabetização.

\section{REFLECTIONS ON THE PNAIC TEACHER TRAINING PROPOSAL FOR CHILD EDUCATION}

\section{ABSTRACT}

Between 2017/2018, the Ministry of Education included the stage, Early Childhood Education, in the National Pact for Literacy in the Right Age (PNAIC), leading to reflection on themes related to curricular policies and teacher training that work in this context. The objective of this bibliographic study is to discuss the implementation of this program in Early Childhood Education. Initially, we conducted a historical rescue on the PNAIC. Subsequently, we present the conception of children and childhood, based on the concepts that have been constituted throughout history in Brazil. Afterwards, we present an analysis of the frameworks that support the pedagogical action in Early Childhood Education. Finally, we performed an analysis of the proposal built, in an attempt to elucidate its repercussion in educational practices.

Keywords: National Pact for Literacy in the Right Age. Child education. Literacy.

\section{REFLEXIONES SOBRE LA PROPUESTA DE FORMACIÓN DE PROFESORES DEL PNAIC PARA LA EDUCACIÓN INFANTIL}

\section{RESUMEN}

Entre el 2017/2018, el Ministerio de la Educación incluyó la etapa, Educación Infantil, en el Programa Pacto Nacional por la Alfabetización en la Edad Correcta - PNAIC -, eso nos provocó una reflexión sobre las temáticas relacionadas a las políticas curriculares y formación de los profesores que actúan en ese contexto. El objetivo de este estudio bibliográfico es discutir la implementación de ese programa en la Educación Infantil. Inicialmente, realizamos una revisión histórica sobre el PNAIC. Posteriormente, presentamos la concepción de niño y de infancia, a partir de los conceptos que se constituyeron en diferentes momentos de la historia de Brasil. Después, presentamos un análisis de los hitos que sostienen la acción pedagógica en la Educación Infantil. Finalmente, realizamos un análisis de la propuesta construida por el PNAIC, en el intento de dilucidar su repercusión en las prácticas educativas.

Palabras clave: Pacto Nacional por la Alfabetización en la Edad Correcta. Educación Infantil. Alfabetización.

Submetido em 02 de fevereiro de 2019 Aceito em 30 de agosto de 2019 